\section{Efficacy and side effects of 'swinging eyelid' orbital decompression in Graves' orbitopathy: a proposal for standardized evaluation of diplopia}

D Paridaens, A Lie, RJ Grootendorst and WA van den Bosch
Department of Oculoplastic and Orbital Surgery, Rotterdam Eye Hospital, Rotterdam, The Netherlands

Correspondence:

D Paridaens, Department of Oculoplastic and Orbital Surgery, The Rotterdam Eye Hospital, PO Box 70030, 3000 LM Rotterdam, The Netherlands Tel: + 310104017777 ; Fax: + 310104111747 E-mail: paridaens@ icapi.nl

Received: 14 September 2004

Accepted: 1 December 2004

Published online: 4 March 2005

\begin{abstract}
Objectives To evaluate the efficacy and side effects of 'swinging eyelid' orbital decompression in patients with Graves' orbitopathy (GO). To calculate the incidence of postoperative new-onset diplopia (NOD) using a newly proposed scoring system for diplopia.

Methods We reviewed the clinical data on proptosis, visual acuity, and diplopia in 104 consecutive patients (198 orbits) with GO, who underwent orbital decompression. A combined lateral canthal and inferior fornix incision ('swinging eyelid' approach) was used for removal of the medial wall, the orbital floor and, if indicated, the lateral wall. Indications for surgery were disfiguring/ congestive GO (DGO) in 79 patients (149 orbits) and compressive optic neuropathy (CON) in 25 patients (49 orbits). Diplopia was scored according to four grades. In both groups, the incidence of new-onset (continuous) diplopia (NOD), deterioration of diplopia (DOD), and improvement of diplopia (IOD) were calculated, using strictly defined criteria. Our data on NOD were compared to those from other series, after recalculation according to our criteria.

Results The mean proptosis reduction was $4.6 \mathrm{~mm}$ (range 0-9.5 mm) after three-wall decompression ( 95 patients, 180 orbits) vs $3.1 \mathrm{~mm}$ (range $0-7 \mathrm{~mm}$ ) after two-wall decompression (nine patients, 18 orbits). The visual acuity improved in $98 \%$ of the patients with CON. In patients with DGO, NOD
\end{abstract}

occurred in $14 \%$. In patients with CON, NOD was not observed, but DOD occurred in $41 \%$. Our data compare favourably to the reported incidence of NOD after either transantral or transnasal decompression.

Conclusions 'Swinging eyelid' orbital decompression is efficacious for proptosis reduction as well as for optic nerve decompression. A scoring system for standardized evaluation of diplopia is proposed.

Eye (2006) 20, 154-162. doi:10.1038/sj.eye.6701827; published online 4 March 2005

Keywords: diplopia; orbital; decompression; thyroid; orbitopathy; Graves

\section{Introduction}

In Graves' orbitopathy (GO), orbital decompression is indicated when optic nerve compression threatens visual function, despite immunosuppression. Furthermore, it may be used to treat disfiguring exophthalmos in patients with noncompressive GO. ${ }^{1}$

Postoperative diplopia is the most frequently reported side effect of orbital decompression using bone removal techniques, especially in patients with compressive optic neuropathy $(\mathrm{CON}){ }^{1}$

Transantral as well as transnasal orbital decompression have been reported to induce diplopia in up to $73 \%$ of patients. ${ }^{2-20}$ After translid, transconjunctival, transcaruncular, ${ }^{21-30}$ and coronal orbital decompression, ${ }^{25,30-33}$ as 
well as after combinations of these techniques, ${ }^{34-40}$ diplopia was observed less frequently, while orbital fat removal seems to carry the lowest risk of inducing diplopia. ${ }^{41-42}$

Recently, we reported on a modified 'swinging eyelid' approach for two- or three-wall orbital decompression in 19 patients with GO. ${ }^{26}$ Here, we report on the efficacy and side effects of this technique in a consecutive series of 104 patients, which includes the patients on whom we reported previously. We compare our data on induced diplopia with those from previous studies. This is hampered by the lack of a uniform scoring system. ${ }^{9,25}$ Therefore, we propose a new scoring system, which we use to calculate the incidence of induced diplopia in our series and in previously published series. $^{3-13,16,18,20,22-35,37-39}$

\section{Patients and methods}

Between January 1998 and February 2002, 104 consecutive patients (198 orbits) suffering from GO underwent 'swinging eyelid' orbital decompression. A total of 95 patients (180 orbits) were treated with a threewall decompression and nine patients (18 orbits) with a two-wall (infero-medial) decompression. CON was diagnosed when there was a decrease in VA associated with disturbed colour vision and/or visual field defect, and/or abnormal visual-evoked potentials (VEPs), and/ or optic disk oedema. Proptosis measurements were performed utilizing calibrated prism-type Hertel exophthalmometers (manufactured by Rodenstock and by Marco). For analysis, we used clinical and orthoptic data obtained shortly preoperatively and at 2 months postoperatively. Of all patients we obtained information on age, sex, smoking, thyroid disease, a family history of Graves' disease and the presence of diabetes mellitus. Pre- and postoperative orthoptic data were available of all 79 patients with disfiguring GO (DGO) (100\%) and of 24 out of 25 patients with CON (96\%).

One orthoptist (RG) classified the pre- and postoperative (binocular) diplopia according to a (subjective) scale (Table 1).

\section{Statistics}

Fisher's exact test was used to calculate the significance of differences between the groups of patients with respectively DGO and CON.

\section{Calculation of incidence of diplopia}

The incidence of new-onset (continuous) diplopia (NOD) was calculated by dividing the number of patients with preoperative grade 0 diplopia and postoperative grade 3 diplopia by the total number of patients with preoperative grade 0 diplopia $\times 100(\%)$. Note that the patients with preoperative grade 1,2 , or 3 are not included in this calculation (Table 2).

The incidence of deterioration of diplopia (DOD) was calculated by dividing the number of patients with preoperative grade 0,1 , or 2 diplopia who postoperatively had a higher grade of diplopia by the total number of patients with preoperative grade 0,1 , or 2 diplopia $\times 100(\%)$. Note that the patients with preoperative grade 3 diplopia are not included in this calculation. Also note this calculation includes the patients with NOD (Table 2).

The incidence of improvement of diplopia (IOD) was calculated by dividing the number of patients with preoperative grade 1,2 , or 3 diplopia who postoperatively had a lower grade of diplopia by the total number of patients with preoperative grade 1,2 , or 3 diplopia $\times 100(\%)$. Note that patients with preoperative grade 0 diplopia are logically not included in this calculation (Table 2).

\section{Surgical technique}

The three-wall decompression technique using the 'swinging eyelid' approach is described briefly. For a

Table 1 Grades of diplopia

\begin{tabular}{ll} 
Grades of diplopia \\
\hline 0 & No diplopia \\
1 & Gaze-evoked diplopia \\
2 & Discontinuous diplopia in primary and/or reading position \\
3 & Continuous diplopia in primary and/or reading position \\
\hline
\end{tabular}

Table 2 Calculation of new-onset diplopia (NOD), deterioration of diplopia (DOD), and improvement of diplopia (IOD)

New-onset continuous

diplopia (\%): $\quad \frac{n(0 \rightarrow 3) 100}{n(0)}$

Deterioration of diplopia (\%):

$$
\frac{n(0 \rightarrow 1,2,3)+n(1 \rightarrow 2,3)+n(2 \rightarrow 3) 100}{n(0,1,2)}
$$

Improvement of diplopia (\%):

$$
\frac{n(1 \rightarrow 0)+n(2 \rightarrow 1,0)+n(3 \rightarrow 2,1,0) 100}{n(1,2,3)}
$$

$n$ : number of patients. $0-3$ : grades of diplopia. $n(0 \rightarrow 3)$ : number of patients with postoperative increase of diplopia grade from 0 to 3 . 
more detailed description, we refer to our previous publication on this topic. ${ }^{26}$ The lateral canthus and inferior fornix are incised, up to the mucocutaneous margin of the medial canthus, inferomedially of the caruncle. The inferior part of the lateral canthal ligament is cut and the eyelid is rotated inferiorly (the 'swinging eyelid approach'). Any protruding orbital fat is excised (internal blepharoplasty). The periosteum is incised along the inferior, and lateral orbital rim and the periorbita is separated bluntly from the medial, inferior, and lateral orbital walls. The orbital walls are (partially) removed $a b$ interno, leaving the orbital rim and the temporalis muscle intact. To limit downward displacement of the eyeball, the anterior $1 \mathrm{~cm}$ of the orbital floor is left in place. In patients with mild to moderate degrees of proptosis (ie exophthalmometry values $<22 \mathrm{~mm}$ ), we attempt to spare the inferomedial orbital strut (ie the bony joint between the medial orbital floor and medial wall), since its removal may cause an inferomedial shift of the orbital contents. The periorbita is incised in a posterior-anterior direction medially, infero-medially, and laterally. Approximately $1-1.5 \mathrm{~cm}$ of the anterior periorbita is left intact. Herniation of fat is augmented through blunt dissection with scissors in the spaces between the rectus muscles. In most patients with limited exophthalmos, the lateral wall is not removed to avoid overcorrection (enophthalmos).

\section{NOD after orbital decompression: a review of the literature and recalculation}

We used the Pubmed database to search for reports on various techniques of orbital decompression in patients with GO, dating from 1980 to 2003. For analysis, we included larger studies that included data on diplopia. If possible, we reanalysed the data on diplopia using our method described previously.

\section{Results}

We included 198 orbits of 104 consecutive patients. The clinical data on sex, age, thyroid disease, smoking habits, familial occurrence of Graves' disease, and presence of coexistent diabetes mellitus are summarized in Table 3.

The indication for surgery was DGO in 79 patients (149 orbits) and CON in 25 patients (49 orbits). In the first group, three patients had (bilateral) exposure keratopathy.

Of the 79 patients with DGO, $12(15 \%)$ had a familial history of Graves' disease, vs seven of the 25 patients with CON (28\%) (Table 3) $(P>0.05)$. Diabetes mellitus occurred in three patients with DGO $(4 \%)$ and in five patients with CON $(20 \%)(P<0.05)$. In the CON group, the mean age was higher $(P<0.05)$ and there were relatively more smokers $(P>0.05)$.

\section{Proptosis reduction}

In patients treated with three-wall decompression ( $n=95,180$ orbits), the mean proptosis reduction was $4.6 \mathrm{~mm}$ (range $0-9.5 \mathrm{~mm}$ ). In two patients (four orbits), the proptosis reduction was $1.5 \mathrm{~mm}$ or less, despite adequate bone removal according to postoperative CT-scans.

In patients treated with two-wall decompression ( $n=9,18$ orbits), the mean proptosis reduction was $3.1 \mathrm{~mm}$ (range 0.5 to $-8 \mathrm{~mm}$ ). The preoperative exophthalmometry was less than $25 \mathrm{~mm}$ in all patients but one.

The mean proptosis reduction was $4.1 \mathrm{~mm}$ in patients with $\mathrm{CON}$ and $4.6 \mathrm{~mm}$ in patients with DGO patients (Figure 1).

\section{Visual acuity}

In the patients with CON, the mean VA increased from, on average, 0.54 to 0.85 . It improved in 24 of the 25 patients, in 48 of the 49 operated orbits, and did not change in one orbit, of one patient with diabetes mellitus.

\section{Diplopia frequency}

In patients with DGO, NOD (ie progression of grade 0 to grade 3) occurred in seven out of 49 patients (14\%)

(Table 4). DOD (including NOD) occurred in 30 out of 77

Table 3 Clinical aspects of 104 consecutive patients with Graves' orbitopathy who underwent 'swinging eyelid' two- or three-wall orbital decompression

\begin{tabular}{|c|c|c|c|c|c|c|c|c|c|}
\hline & \multicolumn{2}{|c|}{ Sex } & \multirow{2}{*}{$\frac{\text { Age (years) }}{\text { Av (range) }}$} & \multicolumn{3}{|c|}{ Thyroid disease } & \multirow[t]{2}{*}{ Smoking } & \multirow[t]{2}{*}{ Fam Graves } & \multirow[t]{2}{*}{$D M$} \\
\hline & Male & Female & & Hyperthyroid & Euthyroid & Hypothyroid & & & \\
\hline DGO & $13 \%$ & $87 \%$ (69) & 42 (17-65) & $91 \%(72)$ & $6 \%(5)$ & $3 \%(2)$ & $41 \%(32)$ & $15 \%$ & $4 \%(3)$ \\
\hline $\mathrm{CON}$ & $20 \%(5)$ & $80 \%(20)$ & $56(38-78)$ & $88 \%(22)$ & 0 & $12 \%(3)$ & $56 \%(14)$ & $28 \%(7)$ & $20 \%(5)$ \\
\hline Total & $14 \%$ & $86 \%$ (89) & $45(17-78)$ & $91 \%$ (97) & $5 \%(5)$ & $5 \%(5)$ & $44 \%$ & $18 \%$ (19) & $8 \%(8)$ \\
\hline
\end{tabular}


patients (39\%) and IOD occurred in 14 out of 30 patients $(3 \%)$.

In patients with $\mathrm{CON}, \mathrm{NOD}$ was not observed in the five patients at risk. DOD, however, occurred in seven out of 17 patients (41\%), while IOD occurred in one out of 17 patients $(6 \%)$ (Table 5$)$.

\section{Other side effects and complications}

Other side effects included transient $(n=23)$ and permanent $(n=3)$ hypesthesia of the infraorbital nerve area ( $n=26$ (patients), 24\%) and transient corneal erosion
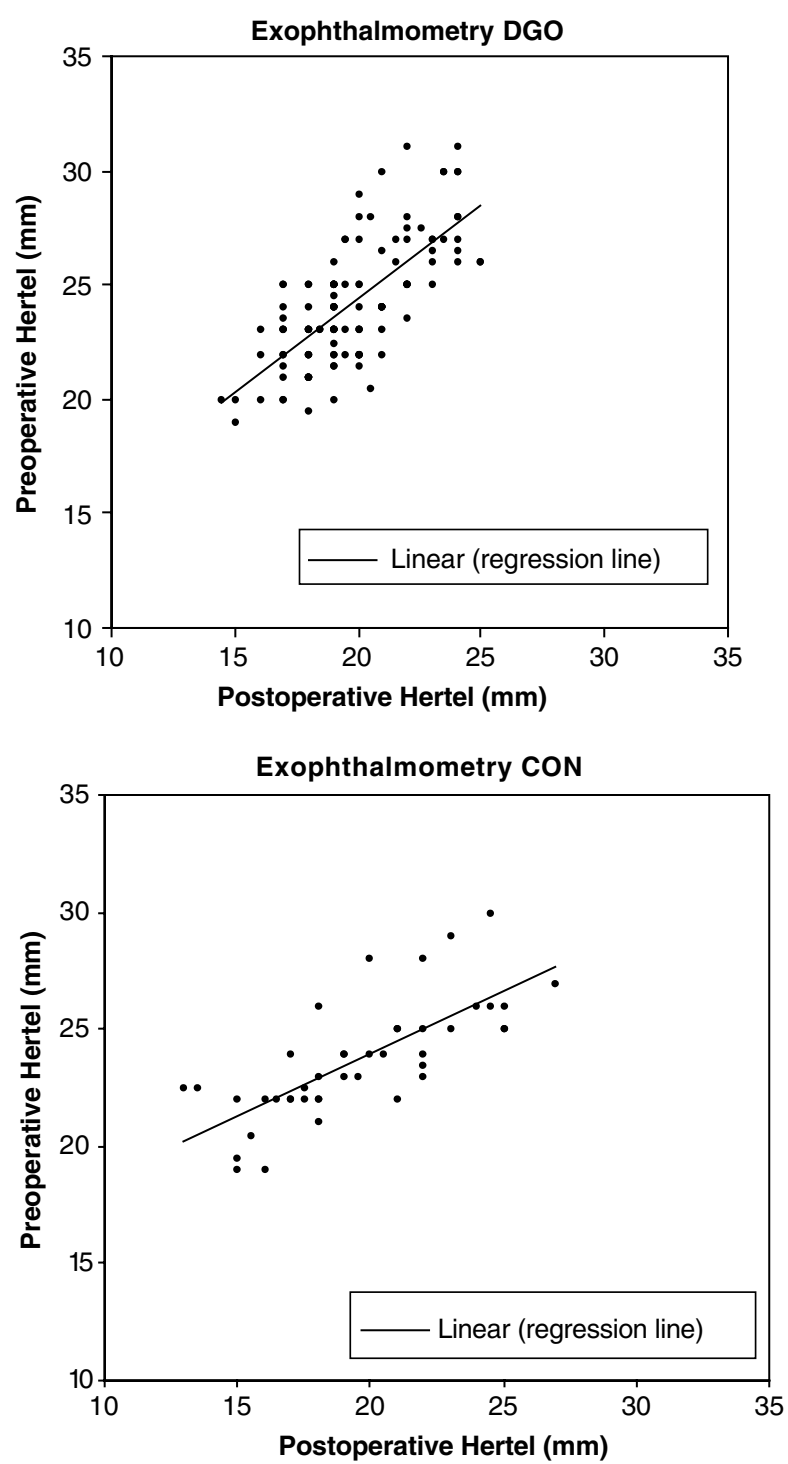

Figure 1 Exophthalmometry (Hertel) values measured shortly prior to orbital decompression and at 2 months afterwards. Top: data of 79 patients (149 orbits) with DGO. Bottom: data of 25 patients (49 orbits) with CON.
( $n=3,3 \%$ ). A minor but noticeable downward shift of the operated eye(s) was seen in four patients (4\%). One patient developed an abscess near the temporal canthus. In two patients, a unilateral postoperative haematoma required surgical drainage. In one DGO patient, who underwent bilateral two-wall decompression, both lateral walls were removed additionally because of insufficient proptosis reduction. Cerebrospinal fluid (CSF) leakage occurred in two patients. In one patient, a

Table 4 Pre- and postoperative diplopia score in 79 patients with DGO

\begin{tabular}{|c|c|c|c|c|}
\hline $\begin{array}{r}\text { Postoperative } \\
\text { Preoperative }\end{array}$ & 0 & 1 & 2 & 3 \\
\hline 0 & $\mathbf{2 7}$ & $\mathbf{9}$ & $\mathbf{6}$ & $\mathbf{7}$ \\
\hline 1 & & $\mathbf{1 2}$ & & $\mathbf{5}$ \\
\hline 2 & 2 & 2 & $\mathbf{4}$ & $\mathbf{3}$ \\
\hline 3 & & & & $\mathbf{2}$ \\
\hline
\end{tabular}

$0=$ no diplopia

1 = gaze-evoked diplopia.

$2=$ discontinuous diplopia in primary and/or reading position

$3=$ continuous diplopia in primary or reading position

$\square=$ regression of diplopia.

$\square=$ progression of diplopia.

$\square=$ no change in diplopia.

Table 5 Pre- and postoperative diplopia score in 23 patients with CON

\begin{tabular}{|c|c|c|c|c|}
\hline $\begin{array}{r}\text { Postoperative } \\
\text { Preoperative }\end{array}$ & 0 & 1 & 2 & 3 \\
\hline 0 & $\mathbf{5}$ & $\mathbf{2}$ & & \\
\hline 1 & & $\mathbf{4}$ & & $\mathbf{5}$ \\
\hline 2 & & 1 & & \\
\hline 3 & & & & $\mathbf{7}$ \\
\hline
\end{tabular}

$0=$ no diplopia

1 = gaze-evoked diplopia.

$2=$ discontinuous diplopia in primary and/or reading position

$3=$ continuous diplopia in primary or reading position

$\square=$ improvement of diplopia.

$\square=$ aggravation of diplopia.

$\square=$ no change in diplopia. 
dural defect at the deep lateral wall was closed with temporalis muscle fascia. In the second patient, CSF leakage from the orbital apex was managed with a lumbal drain for 5 days.

\section{NOD after orbital decompression: a review of the literature and recalculation}

NOD following different surgical techniques

Table 6 shows the reported and, if possible, recalculated incidence of NOD after orbital decompression with different techniques in 34 reports dating from 1980 to $2003,^{3-13,16,18,20,22-35,37-42}$ as well as the results from this study. Analysis was hampered by several factors such as lack of information on the definition(s) and grading of diplopia, lack of information regarding the indications for surgery, the use of different (or combinations of) surgical techniques, and variable follow-up.

In eight studies, the recalculated frequency of NOD proved higher than the reported frequency (Table 6). In these studies, the incidence of NOD had been calculated by dividing the number of patients with NOD by the total number of included patients rather than by the subset of patients without preoperative diplopia. In 16 studies we found no difference between the recalculated and the reported frequency of NOD. The data from the remaining 10 studies proved inadequate for recalculation.

In 11 studies on transantral decompression, the reported incidence of NOD ranged from $22^{9}$ to $73 \% .^{14}$ After recalculation, the incidence ranged from 64 to $73 \%$. The highest incidence was reported after decompression because of DGO. ${ }^{11}$ Interestingly, no case of NOD was reported in one series on a modified technique for transantral decompression. ${ }^{22}$

In 16 studies on transconjunctival, transcaruncular, and translid decompression, the reported incidence of NOD ranged from $0^{25}$ to $33 \% .{ }^{31}$ In one of these studies, ${ }^{28}$ the reported incidence of NOD was $9 \%$ vs a recalculated value of $25 \%$. In five other studies, a combined transnasal and translid/transconjunctival approach was used, with a reported incidence of NOD ranging from $0^{34,35}$ to $12 \% .^{40}$ In three of these, data were insufficient for recalculation, in the other two the reported value did not differ from the recalculated value. In five studies on coronal orbital decompression, the reported incidence of NOD ranged from $3^{33}$ to $33 \%{ }^{31}$ before recalculation, and from $8^{33}$ to $50 \%^{32}$ after recalculation.

In three studies on transnasal decompression, the reported incidence of NOD ranged from $22^{20}$ to $29 \%^{18}$ before recalculation, and from $44^{18}$ to $58 \%{ }^{16}$ after recalculation. After recalculation, a comparable high frequency of NOD was found in one study that predominantly contained patients with $\mathrm{CON}^{16}$ and in two studies that predominantly contained patients with DGO. ${ }^{18,20}$

In two studies on decompression by orbital fat removal, the reported (and recalculated) frequency of NOD ranged from 0 to $3 \% .^{41,42}$

NOD and indication for surgery

In only three studies, ${ }^{4,24,37}$ in which both patients with DGO and those with CON were included, the authors had calculated the incidence of NOD according to the indication for surgery. In these studies, the reported (and recalculated) incidence of NOD ranged from 30 to $86 \%$ in patients with $\mathrm{CON}$ and from 10 to $32 \%$ in patients with DGO.

\section{Discussion}

The exophthalmos reduction achieved with 'swinging eyelid' orbital decompression is comparable to that achieved with other bony decompression techniques (Table 6).

Interestingly, in two patients (four orbits) we achieved an exophthalmos reduction of less than $1.6 \mathrm{~mm}$, despite adequate bony decompression. Postinflammatory fibrosis of the orbital tissues as well as inadequate opening of the periorbita may limit the prolapse of the orbital tissues. Furthermore, when the disease is still active, the orbital tissues may further expand postoperatively and thus restrict the clinical effect of the procedure.

The overall improvement of visual acuity in our series is comparable to that reported after either transantral or transnasal decompression. ${ }^{10,16}$ This does not support the assumption held by some authors that transconjunctival decompression may be less effective in the treatment of optic nerve compression. ${ }^{5,27}$ It may, however, well be that - in our study - the medial precaruncular extension of the transconjunctival incision added to the exposure of the medial wall. Both the transcaruncular ${ }^{27}$ and the precaruncular $^{43}$ approach can be used in combination with the transconjunctival route and may facilitate excellent exposure of the medial wall.

\section{NOD after orbital decompression: a review of the literature and recalculation}

Recalculation in 24 out of 34 published reports showed a remarkably higher frequency of NOD in eight studies (33\%). This proved due to the inclusion in this calculation of all treated patients, including those who were already suffering from diplopia prior to surgery. Therefore, in the future, standardized criteria should be used to calculate the frequency of NOD. 
Table 6 Incidence of new onset (continuous) diplopia (NOD) following orbital decompression through different techniques. Comparison between authors' values and values from recalculation using the proposed definition and method

\begin{tabular}{|c|c|c|c|c|c|c|}
\hline \multirow[t]{2}{*}{$\begin{array}{l}\text { First author } \\
\text { (year of publication) }\end{array}$} & \multirow[t]{2}{*}{ Technique $e^{\mathrm{a}}$} & \multicolumn{3}{|c|}{$\begin{array}{c}\text { Indication } \\
\text { (number of patients) }\end{array}$} & \multicolumn{2}{|c|}{$\begin{array}{l}\text { New-onset } \\
\text { diplopia }\end{array}$} \\
\hline & & CON & $D G O$ & Total & Authors & Recalc value ${ }^{\mathrm{b}}$ \\
\hline \multirow[t]{2}{*}{ DeSanto (1980) } & \multirow[t]{2}{*}{ Transantral } & \multirow[t]{2}{*}{194} & & \multirow[t]{2}{*}{3200} & $?$ & $55 \%(52 / 94)$ \\
\hline & & & 6 & & $?$ & $67 \%(4 / 6)$ \\
\hline \multirow[t]{2}{*}{ Shorr (1982) } & Transantral $(n=45) /$ & \multirow[t]{2}{*}{15} & & \multirow[t]{2}{*}{350} & $44 \%(4 / 9)$ & Idem $^{c}$ \\
\hline & Transconjunctival $(n=5)$ & & 35 & & $32 \%(8 / 25)$ & Idem \\
\hline \multirow[t]{2}{*}{ McCord (1985) } & Translid & 58 & & \multirow[t]{2}{*}{370} & $4 \%$ & $?$ \\
\hline & Transantral & 12 & & & $33 \%$ & $?$ \\
\hline \multirow[t]{2}{*}{ Shorr (1986) } & Transantral & 28 & 14 & 42 & $22 \%(9 / 42)$ & $64 \%(9 / 14)$ \\
\hline & Transconj & $?$ & $?$ & 17 & $12 \%(2 / 17)$ & $17 \%(2 / 12)$ \\
\hline \multirow{2}{*}{ Fells (1987) } & Transantral & $15 ?$ & & \multirow[t]{2}{*}{329} & $?$ & $27 \%(4 / 15) ?$ \\
\hline & Lynch & $14 ?$ & & & $?$ & $79 \%(11 / 14) ?$ \\
\hline Warren (1989) & Transantral & $302 ?$ & $3 ?$ & 305 & $67 \%(206 / 305)$ & $?$ \\
\hline Leatherbarrow (1991) & Coronal (3-wall) & 8 & 2 & 10 & ? & $50 \%(3 / 6)$ \\
\hline Garrity (1993) & Transantral & 217 & 211 & 428 & $64 \%(74 / 116)$ & Idem \\
\hline Trokel (1993) & Orbital fat removal (translid) & $?$ & $?$ & 81 & ? & $3 \%(2 / 81)$ \\
\hline Lyons (1994) & Lynch or translid or swinging eyelid & & 34 & 34 & $18 \% ?$ & \\
\hline Tjon (1994) & Transantral & 20 & 55 & 75 & $46 \%(23 / 50)$ & Idem \\
\hline Fatourechi (1994) & Transantral & & 34 & 34 & $73 \%(11 / 15)$ & Idem \\
\hline Hutchison (1995) & Translid & 33 & & 33 & $6 \%(2 / 33)$ & Idem \\
\hline Kalmann (1997) & Coronal (3-wall) & & 125 & 125 & $3 \%(4 / 125)$ & $8 \%(4 / 49)$ \\
\hline McNab (1997) & Lynch/transconj/translid (2 or 3-wall) & 21 & 12 & \} 33 & $30 \%(10 / 33)$ & $8 \%(1 / 12)$ \\
\hline \multirow[t]{2}{*}{ Paridaens (1998) } & Translid (2-wall) & & 29 & 29 & $0 \%(0 / 12)$ & Idem \\
\hline & Coronal (3-wall) & & 41 & 41 & $14 \%(3 / 22)$ & Idem \\
\hline Ulualp (1999) & Transnasal/transconj & 1 & 14 & 15 & $0 \%$ & $?$ \\
\hline Shorr (2000) & Transcaruncular/transconj & 4 & 11 & 15 & $0 \% ?$ & $?$ \\
\hline \multirow[t]{4}{*}{ Goldberg (2000) } & Coronal (2-wall) & 2 & 11 & $6\} 13$ & $33 \%(3 / 9)$ & Idem \\
\hline & $\begin{array}{l}\text { Transcaruncular/transconj } \\
\text { and translid (2-wall) }\end{array}$ & & & $7\}$ & & \\
\hline & Coronal (lat wall) & 2 & 17 & $4\} 19$ & $7 \%(1 / 14)$ & Idem \\
\hline & Translid (lat wall) & & & $15\}$ & & \\
\hline Kazim (2000) & Orbital fat removal (translid) & 5 & & 5 & $0 \%$ & Idem \\
\hline Tallstedt (2000) & Transantral & 40 & 23 & 63 & $51 \%(22 / 43)$ & Idem \\
\hline Paridaens (2000) & Transconj (3 and 2-wall) & 6 & 13 & 19 & $13 \%(1 / 8)$ & Idem \\
\hline Seiff (2000) & Transantral (modified) & 5 & 10 & 15 & $0 \%(0 / 9)$ & Idem \\
\hline Unal (2000) & Translid (lat wall) + transnasal & & & 14 & $0 \%(0 / 7)$ & Idem \\
\hline Michel (2001) & Transnasal & 78 & & 78 & $?$ & $58 \%(21 / 36)$ \\
\hline \multirow[t]{4}{*}{ Liao (2001) } & Transantral (10\%)/ & 323 & & 368 & $21 \%(10 / 48)$ & Idem \\
\hline & Transconj $(71 \%) /$ & \} & 45 & & CON: $86 \%$ & \\
\hline & Lynch $(3 \%) /$ & \} & & & $(6 / 7)$ & \\
\hline & Transcaruncular (16\%) & \} & & & $\begin{array}{l}\text { DGO: } 10 \% \\
(4 / 41)\end{array}$ & \\
\hline Kikkawa (2002) & $\begin{array}{l}\text { Translid (lat wall) }+ \text { orb fat removal, } \\
\pm \text { transconj and transcaruncular } \\
(\text { med }+ \text { inf wall })\end{array}$ & $?$ & $?$ & 323 & $9 \%(2 / 23)$ & $25 \%(2 / 8)$ \\
\hline \multirow[t]{2}{*}{ Metson (2002) } & Transnasal & & 24 & 24 & $29 \%$ & $44 \%(4 / 9)$ \\
\hline & Transnasal with orbital sling & & 13 & 13 & $0 \%$ & $0 \%(0 / 5)$ \\
\hline \multirow[t]{3}{*}{ Unal (2003) } & Translid + transnasal & & 11 & \} 18 & $0 \%(0 / 10)$ & Idem \\
\hline & $($ lat + med wall $)+$ fat resection & & & & & \\
\hline & $\begin{array}{l}\text { Translid + transnasal }+ \\
\text { transconj (3-wall) }\end{array}$ & & 7 & & $57 \%(4 / 7)$ & Idem \\
\hline Schaefer (2003) & Transconj and transnasal (floor + medial wall) & 16 & 25 & 41 & ? & $24 \%(5 / 21)$ \\
\hline Roberts (2003) & Transnasal & 8 & 15 & 23 & $22 \%(5 / 23)$ & $57 \%(8 / 14)$ \\
\hline Vaseghi (2003) & Translid + transnasal $($ med + lat wall \pm floor $)$ & 10 & 16 & 26 & $12 \%(3 / 26)$ & $?$ \\
\hline Graham (2003) & Transcaruncular or transnasal medial & 22 & 18 & 40 & $10 \%(4 / 40)$ & $>15 \%(4 / 27)$ \\
\hline
\end{tabular}


Table 6 (Continued)

\begin{tabular}{|c|c|c|c|c|c|c|}
\hline \multirow[t]{2}{*}{$\begin{array}{l}\text { First author } \\
\text { (year of publication) }\end{array}$} & \multirow[t]{2}{*}{ Technique } & \multicolumn{3}{|c|}{$\begin{array}{c}\text { Indication } \\
\text { (number of patients) }\end{array}$} & \multicolumn{2}{|c|}{$\begin{array}{l}\text { New-onset } \\
\text { diplopia }\end{array}$} \\
\hline & & CON & $D G O$ & Total & Authors & Recalc value ${ }^{\mathrm{b}}$ \\
\hline & wall \pm translid lat wall & & & & & \\
\hline & & & & & CON $0 \%(0 / 9)$ & \\
\hline & & & & & DGO $22 \%$ & \\
\hline \multirow[t]{4}{*}{ Cruz (2003) } & Transconj + transcarunc (2-wall) & $?$ & $?$ & $29\}$ & $14 \%(3 / 22)$ & Idem \\
\hline & & & & \} 53 & & \\
\hline & Coronal (3-wall) & & & \} & & \\
\hline & & $?$ & $?$ & $24\}$ & $17 \%(2 / 12)$ & Idem \\
\hline \multirow[t]{3}{*}{ This study (2004) } & Transconj & & 79 & \} 103 & $14 \%(7 / 49)$ & Idem \\
\hline & (3 and 2-wall) & & & & & \\
\hline & Idem & 24 & & & $0 \%(0 / 7)$ & Idem \\
\hline
\end{tabular}

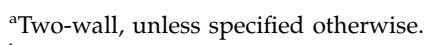

${ }^{b}$ Defined as: number of patients with postoperative diplopia in primary and/or reading position divided by number of patients with no preoperative diplopia $\times 100(\%)$. The percentages were (re-)calculated using published data. Inclusion criteria, definitions of diplopia, and follow-up periods varied. cIdem: as the value reported by authors.

Analysis of previous reports also showed that often no clear distinction is made between patients suffering from CON or DGO. While, in general, NOD seems to occur more frequently in patients with $\mathrm{CON}$, the highest incidence was reported in a series entirely consisting of patients with DGO who underwent transantral decompression. ${ }^{14}$ In contrast, NOD was not reported in a small series of 15 patients treated with a modified transantral technique, in which the anterior $10-15 \mathrm{~mm}$ of periorbita was not incised. ${ }^{22}$ While, after recalculation, the frequency of NOD after transnasal decompression ranged from 44 to $58 \%,{ }^{4}$ no NOD was reported in a series of 13 patients treated with transnasal decompression in whom a horizontal strip of periorbital fascia over the medial rectus muscle ('orbital sling') was preserved. This suggests that the frequency of NOD after either transnasal or transantral decompression may be lowered by modification of the way in which the orbital tissues (eg the periorbita) are opened. Indeed, in a small published series of three patients who were treated with infero-medial decompression without opening of the periorbita, no postoperative diplopia was noted. ${ }^{44}$ Although it was reported that limited opening of the periorbita may result in a lesser amount of retroplacement of the globe, ${ }^{44}$ no difference in proptosis reduction was noted between patients who underwent transnasal orbital decompression using the so-called 'orbital sling' technique and those treated with nonmodified transnasal decompression. ${ }^{18}$

Recalculation of data from studies on anterior approach three-wall orbital decompression, including translid, transconjunctival ('swinging eyelid'), and coronal techniques show relatively low NOD frequencies of 0 to $33 \%$ (Table 6). Although it was speculated that a 'balancing effect' of lateral and medial wall decompression may limit the frequency of NOD, ${ }^{7,24,26,31,35,38}$ recent studies ${ }^{25,30}$ failed to show a difference between translid or transconjunctival two-wall decompression and coronal three-wall decompression in that respect.

In a recent retrospective and nonrandomized study, ${ }^{31}$ 31 patients underwent orbital decompression with either removal of the lateral and medial wall or removal of the lateral wall combined with excision of intraconal orbital fat. The authors concluded that the latter procedure lowers the risk of NOD from 33 to $7 \%$. Orbital decompression through fat removal only seems to carry an even lower risk of NOD. ${ }^{41,42}$ Patients with predominantly extra-ocular muscle enlargement, however, are less likely to benefit from this technique.

In conclusion, 'swinging eyelid' orbital decompression is efficacious for exophthalmos reduction in both DGO and $\mathrm{CON}$, and allows for adequate decompression of the orbital apex. The rate of NOD compares favourably to classic transantral and transnasal two (or one)wall decompression. It remains speculative what factors cause this difference. We propose to use a scoring system with strict definitions of diplopia grades to facilitate future comparison between the results of various decompression techniques in patients with GO.

\section{Acknowledgements}

We thank the SWOO Foundation, Rotterdam for the financial support of this study. 


\section{References}

1 Siracuse-Lee DE, Kazim M. Orbital decompression: current concepts. Curr Opin Ophthalmol 2002; 13: 310-316.

2 Walsh TE, Ogura JH. Transantral orbital decompression for malignant exophthalmus. Laryngoscope 1957; 67: 544-568.

3 DeSanto LW. The total rehabilitation of Graves' ophthalmopathy. Laryngoscope 1980; 90: 1652-1678.

4 Shorr N, Neuhaus RW, Baylis HI. Ocular motility problems after orbital decompression for dysthyroid ophthalmopathy. Ophthalmology 1982; 89: 323-328.

5 McCord Jr CD. Current trends in orbital decompression. Ophthalmology 1985; 92: 21-33.

6 Shorr N, Seiff SR. The four stages of surgical rehabilitation of the patient with dysthyroid ophthalmopathy. Ophthalmology 1986; 93: 476-483.

7 Fells P. Orbital decompression for severe dysthyroid eye disease. Br J Ophthalmol 1987; 71: 107-111.

8 Warren JD, Spector JG, Burde R. Long-term follow-up and recent observations on 305 cases of orbital decompression for dysthyroid orbitopathy. Laryngoscope 1989; 99: 35-40.

9 Garrity JA, Fatourechi V, Bergstralh EJ, Bartley GB, Beatty CW, DeSanto LW et al. Results of transantral orbital decompression in 428 patients with severe Graves' ophthalmopathy. Am J Ophthalmol 1993; 116: 533-547.

10 Tjon F, Sang M, Knegt P, Wijngaarde R, Poublon R, van der Schans $\mathrm{E}$ et al. Transantral orbital decompression for Graves disease. Clin Otolaryngol 1994; 19: 290-294.

11 Fatourechi V, Garrity JA, Bartley GB, Bergstralh EJ, De Santo LW, Gorman CA. Graves ophthalmopathy, results of transantral orbital decompression performed primarily for cosmetic indications. Ophthalmology 1994; 101: 938-942.

12 Tallstedt L, Papatziamos G, Lundblad L, Anggard A. Results of transantral orbital decompression in patients with thyroid-associated ophthalmopathy. Acta Ophthalmol Scand 2000; 78: 206-210.

13 Seiff SR, Tovilla JL, Carter SR, Choo PH. Modified orbital decompression for dysthyroid orbitopathy. Ophthal Plast Reconstr Surg 2000; 16(1): 62-66.

14 Neugebauer A, Nishino K, Neugebauer P, Konen W, Michel O. Effects of bilateral orbital decompression by an endoscopic endonasal approach in dysthyroid orbitopathy. Br J Ophthalmol 1996; 80: 58-62.

15 May A, Fries U, Reimold I, Weber A. Microsurgical endonasal decompression in dysthyroid orbitopathy. Acta Otolaryngol 1999; 119: 826-831.

16 Michel O, Oberländer N, Neugebauer P, Neugebauer A, Russmann W. Follow-up of transnasal orbital decompression in severe Graves' ophthalmopathy. Ophthalmology 2001; 108: 400-404.

17 Paridaens D, van den Bosch W. Comment on: follow-up of transnasal orbital decompression in severe Graves' ophthalmopathy. Ophthalmology 2001; 108: 215-216.

18 Metson R, Samaha M. Reduction of diplopia following endoscopic orbital decompression:the orbital sling technique. Laryngoscope 2002; 112(10): 1753-1757.

19 Wee DT, Carney AS, Thorpe M, Wormald PJ. Endoscopic orbital decompression for Graves' ophthalmopathy. J Laryngol Otol 2002; 116: 6-9.

20 Roberts CJ, Murphy MF, Adams GG, Lund VJ. Strabismus following endoscopic orbital decompression for thyroid eye disease. Strabismus 2003; 11(3): 163-171.
21 McCord Jr CD. Orbital decompression for Graves' disease. Exposure through lateral canthal and inferior fornix incision. Ophthalmology 1981; 88(6): 533-541.

22 Lyons CJ, Rootman J. Orbital decompression for disfiguring exophthalmos in thyroid orbitopathy. Ophthalmology 1994; 101: 223-230.

23 Hutchison BM, Kyle PM. Long-term visual outcome following orbital decompression for dysthyroid eye disease. Eye 1995; 9: 578-581.

$24 \mathrm{McNab}$ AA. Orbital decompression for thyroid orbitopathy. Aust NZ J Ophthalmol 1997; 25(1): 55-61.

25 Paridaens D, Hans K, van Buitenen S, Mourits MP. The incidence of diplopia following coronal and translid orbital decompression in Graves' orbitopathy. Eye 1998; 12: 800-805.

26 Paridaens DA, Verhoeff K, Bouwens D, van Den Bosch WA et al. Transconjunctival orbital decompression in Graves' ophthalmopathy: lateral wall approach ab interno. $\mathrm{Br} J$ Ophthalmol 2000; 84: 775-781.

27 Shorr N, Baylis HI, Goldberg RA, Perry JD. Transcaruncular approach to the medial orbit and orbital apex. Ophthalmology 2000; 107: 1459-1463.

28 Kikkawa DO, Pornpanich K, Cruz Jr RC, Levi L, Granet DB. Graded orbital decompression based on severity of proptosis. Ophthalmology 2002; 109(7): 1219-1224.

29 Graham SM, Brown CL, Carter KD, Song A, Nerad JA. Medial and lateral orbital wall surgery for balanced decompression in thyroid eye disease. Laryngoscope 2003; 113: $1206-1209$.

30 Cruz AAV, Leme VR. Orbital decompression: a comparison between trans-fornix/transcaruncular inferomedial and coronal inferomedial plus lateral approaches. Ophthal Plast Reconstr Surg 2003; 19(6): 440-445.

31 Goldberg RA, Perry JD, Hortaleza V. Strabismus after balanced medial plus lateral wall only orbital decompression for dysthyroid orbitopathy. Ophthalmic Plast Reconstr Surg 2000; 16: 271-277.

32 Leatherbarrow B, Lendrum J, Mahaffey PJ, Noble JL, Kwartz J, Davies H. Three wall orbital decompression for Graves' ophthalmopathy via a coronal approach. Eye 1991; 5: $456-465$.

33 Kalmann R, Mourits MP, van der Pol JP, Koornneef L. Coronal approach for rehabilitative orbital decompression in Graves' ophthalmopathy. Br J Ophthalmol 1997; 81: 41-45.

34 Ulualp SO, Massaaro BM, Toohill RJ. Course of proptosis in patients with Graves' disease after endoscopic orbital decompression. Laryngoscope 1999; 109: 1217-1222.

35 Unal M, Ileri F, Konuk O, Hasanreisogglu B. Balanced orbital decompression in Graves' orbitopathy: upper eyelid crease incision for extended lateral wall decompression. Orbit 2000; 19(2): 109-117.

36 van der Wal KG, de Visscher JG, Boukes RJ, Smeding B. Surgical treatment of Graves orbitopathy: a modified balanced technique. Int J Oral Maxillofac Surg 2001; 30: 254-258.

37 Liao SL, Kao SC, Hou PK, Chen MS. Results of orbital decompression in Taiwan. Orbit 2001; 20(4): 267-274.

38 Unal M, Leri F, Konuk O, Hasanreisoglu B. Balanced orbital decompression combined with fat removal in Graves ophthalmopathy: do we really need to remove the third wall? Ophthal Plast Reconstr Surg 2003; 19(2): 112-118.

39 Schaefer SD, Soliemanzadeh P, Della Rocca DA, Yoo GP, Maher EA, Milite JP et al. Endoscopic and transconjunctival 
orbital decompression for thyroid-related orbital apex compression. Laryngoscope 2003; 113(3): 508-513.

40 Vaseghi M, Tarin TT, Levin PS, Terris DJ. Minimally invasive orbital decompression for Graves' ophthalmopathy. Ann Otol Rhinol Laryngol 2003; 112(1): 57-62.

41 Trokel S, Kazim M, Moore S. Orbital fat removal. Decompression for Graves' orbitopathy. Ophthalmology 1993; 100(5): 674-682.
42 Kazim M, Trokel SL, Acaroglu G, Elliott A. Reversal of dysthyroid optic neuropathy following orbital fat decompression. Br J Ophthalmol 2000; 84(6): 600-605.

43 Moe KS. The precaruncular approach to the medial orbit. Arch Facial Plast Surg 2003; 5: 483-487.

44 Harvey JT. Orbital decompression for Graves' disease leaving the periosteum intact. Ophthal Plast Reconstr Surg 1989; 5(3): 199-206. 